Article

\title{
Multidimensional Web GIS Approach for Citizen Participation on Urban Evolution
}

\author{
Frederick Lafrance ${ }^{1, *}$, Sylvie Daniel ${ }^{1}$ and Suzana Dragićević ${ }^{2}$ (i) \\ 1 Department of Geomatics Sciences; Université Laval, Québec, QC G1V 0A6, Canada; \\ sylvie.daniel@scg.ulaval.ca \\ 2 Department of Geography; Simon Fraser University, Burnaby, BC V5A 1S6, Canada; suzanad@sfu.ca \\ * Correspondence: frederick.lafrance.1@ulaval.ca
}

Received: 12 March 2019; Accepted: 26 May 2019; Published: 30 May 2019

\begin{abstract}
Web-mapping has been widely used to facilitate citizen participation in smart cities. Web-mapping has evolved from 2D static maps towards more dynamic and immersive 3D worlds such as virtual globes and scenes. Although current technologies allow us to build multidimensional representations, there is still a lack of research studies on how to further leverage them to foster citizen participation. Information on space-time changes can be an important asset for a successful citizen participation process. Citizens may need to track the evolution of their city over space and time, and how their participation will impact the urban planning and decision-making process. Consequently, the main objective of this research study is to design and develop a multidimensional (2D, 3D, 4D) web-mapping platform where citizens can better assess and understand the spatiotemporal evolution of their cities. User testing was conducted to assess the multidimensional representation of the animations used, and the spatiotemporal mechanism and interface features. Results showed that it is recommended to integrate spatiotemporal simulations to citizen participation platforms so citizens can better assess the impacts of their choices. We also assessed that 3D does not always communicate information better than 2D. Future work will aim at testing the platform in a consultation process with a representative sample of participants.
\end{abstract}

Keywords: geovisualization; web-mapping; spatiotemporal; 2D/3D cartographic representation; citizen participation

\section{Introduction}

Citizen participation helps to strengthen democracy and the public interest by providing them with opportunities to get involved [1]. According to the literature, citizen participation can increase the confidence of citizens in government as well as their influence in the decision-making process. This could help to achieve one of the main objectives of citizen participation, which is to increase the number of committed and engaged citizens in the decision and planning process [2].

Recently, Marzouki et al. [3] defined the citizen participation process (CPP) as one where citizens can share their context of life by communicating their problems, intentions, and objectives. It was argued that the CPP benefits from geovisualization and the addition of spatial and temporal dimensions so that citizens can be informed with credible and current information. Another issue of interest for citizens is the ability to visualize how the city landscape evolves through time [4,5]. As noted by Molinari and Nabatchi [2,6], citizens want to follow the evolution of their city and the impact of their participation on this evolution.

Traditional consultation methods, such as paper questionnaires or public consultation meetings, while still used today, favor neither accessibility nor anonymity of participants. These methods of participation are almost always held in a fixed place and time, often when people are at work or in the 
evening, when other commitments prevent them from attending or fully participating in meetings [7]. Technologies and, more specifically, information and communication technologies (ICT) present a realistic alternative. This is even more true nowadays given that technologies such as the internet, smart phones, tablets, and computers are becoming more accessible to citizens.

Web-based technologies are often used to facilitate the CPP by making it more inclusive and ensuring stakeholder engagement in a productive way [8]. These web-based technologies make it possible to virtually coordinate many geographically separated users. Anonymity is another benefit of the web that makes some users more comfortable to share their opinions [9]. Among the current web technologies, those that are the most relevant for promoting CPP are wikis, social networks (Facebook, blogs, or twitter), and geovisualization tools $[9,10]$.

There is growing evidence that web-mapping can increase citizen participation initiatives in smart cities [11]. In fact, the spatial dimension on which web maps rely is an important consideration, since over $80 \%$ of information shared within a consultation process has an anchor in geographic space [12]. In this sense, Daniel and Doran [11] note the lack of research harnessing the potential of geomatics for the development of smart cities and communities, for which citizen participation is a key component. Consequently, in our study we explore this path to better integrate geomatics and geovisualization tools to facilitate more effective citizen participation.

Over the last decade, web-based geovisualization tools have been widely used to foster citizen participation. In fact, several cases were reported in the literature showing the benefits of 2D maps to facilitate participatory initiatives within cities [7,9]. Even though 2D maps are good at communicating information in a simple way, they drastically simplify reality and thus do not give credit to the highly complex capabilities of human spatial cognition [13]. In this regard, there are many schools of thinking in the literature regarding which spatial dimension between $2 \mathrm{D}$ and $3 \mathrm{D}$ is better to communicate information [14]. Nevertheless, there is a mutual agreement between scholars that 3D geovisualization can improve the understanding of non-experts by communicating information in a more natural way $[15,16]$. Yin and Shiode [17] pointed out there is no need for non-experts to deal with cartography standards to appreciate 3D. However, Tory et al. suggest that 2D and 3D are complementary and offer better problem resolution than each taken separately [18].

Although 3D has been recently applied to citizen participation $[15,19]$, there is still a lack of research studies leveraging the use of 3D dynamic maps to foster citizen participation. Hence, the literature directly related to $4 \mathrm{D}$ cartography (3D plus time), especially regarding citizen participation, is still relatively small. This is surprising considering that (1) current technologies allow for the building of better dynamic 3D maps than before, (2) computer capabilities have increased and can better handle $3 \mathrm{D}$ graphics, and finally (3) time is an important asset for successful citizen participation [2,6].

The goal of our research study was to design and develop a multidimensional (2D, 3D, 4D) web-mapping platform where users can better assess and understand the time evolution of their cities. The proposed platform was built on top of the open virtual globe Cesium, which is based on JavaScript and WebGL. Therefore, in addition to providing a simple and efficient approach combining a web questionnaire and multidimensional visualizations to promote citizen engagement and improve current participation tools, our research generated a platform prototype as a proof of concept. The platform prototype can be used as a general framework that is customizable to fit the needs of different projects in relatively short implementation time. A platform prototype was implemented and the source code may be shared by contacting the corresponding author. In this paper, we respond to the call of Resch et al. $[13,20]$ for more studies evaluating $4 \mathrm{D}$ representations of spatiotemporal phenomena on the web, so that they can be improved and be more intuitive to the public. We also propose a spatiotemporal simulation mechanism compliant with 2D and 3D web-based visualization as well as citizen participation requirements. In addition, we explore the use of spatiotemporal simulations in a citizen-driven context to visualize the change and impacts during a consultation and so this work is a follow-up from [21]. 


\section{Related Work}

In this section, the focus is on the design of the citizen participation platform involving 2D, 3D, and time representations on which our method is based. We explore the frontal web technology used in previous related projects, then highlight communication and participation features. The rendering performance of 3D on the web as well as the spatial and time representations are also reviewed.

\subsection{D Web-Mapping Tools}

Over the last decade, web-mapping has evolved from 2D maps towards more immersive 3D maps, such as virtual scenes and globes, thanks to the recent advance in WebGL. WebGL has been noted by Alatalo et al. [22] as an attractive technology for effectively generating visualizations in participatory urban planning projects on the web. In previous works, virtual scenes such as Unity, X3DOM, and Three.js have been used extensively to develop tools dedicated to the public $[13,15,20,22]$. Additionally, virtual globes such as Nasa World Wind, Cesium.js, and Skyline were often proved to be very effective in a participatory context [19,23-29]. In fact, virtual globes succeed in citizen participation by offering features available in Google Earth and with which the public is familiar (e.g., zoom, panoramic overview, visualization of planning projects, activation of feature inspection). Lovett et al. [30] underlined the potential of 3D visualization tools to address the challenges of communication, mutual understanding, and mediation in urban planning. However, according to them, more studies are needed to fully understand their effectiveness. They also encourage the application of the latest technology with a more comprehensive and critical evaluation of how they are used and the benefits that this may bring.

\subsection{Communication and Participation Features}

Previous studies have highlighted many participation and communication features in web-mapping applications. In 2010, Wu et al. [29] proposed forums, Bulletin Board System (BBS), emails for users to enter their remarks about any urban planning solution when they are viewing them. Then in 2013, $\mathrm{Hu}$ et al. [19] proposed 3D view-sharing, geo-referenced communication, and user operation sharing. These communication tools were considered important communication and participation assets for participants during the consultation. Next, in 2014, Dambruch et al. [15] proposed a way to upload and share 3D models proposing an alternative to the project under consultation as well as discussion board and questionnaires as means to participate. Using a questionnaire allowed faster and easier statistical evaluation than analyzing free-text feedback given in a discussion board.

\subsection{Performance}

Performance is of critical importance when designing tools dedicated to the public. Poor performance can reduce the public's desire to participate. 3D graphics on the web is still an active topic where scholars and developers are working to improve performance. WebGL has become the norm in terms of 3D graphics on the web. However, WebGL still suffers from a significant performance slowdown of two to five times compared to Windows native built [22]. Previous studies have noted performance limit in the rendering of massive 3D contents on the web $[15,22]$. Chaturvedi et al. [31] proposed a CityGML tile-based strategy to render large 3D city models on the web. The overall process is operated through an importer-exporter called 3DCityDB which produces 2D tiles ready to be rendered into Cesium.js or Google Earth. Recently, Cesium.js 3D-tiles has been emerging as a potential strategy to render massive 3D city models online. Nonetheless, at the time this research was conducted, Cesium.js lacked capabilities to convert CityGML dataset into 3D-tiles.

\subsection{Spatial Representations}

The representation of spatial information is important when designing tools for the public. Although, according to Alatalo et al. [22], there is no particular universal visualization solution for urban planning. Lovett et al. [30] mentioned that it seems to be a matter of selecting the most 
suitable technique for a particular task and to assist in such choices. Nonetheless, having multiple level-of-abstraction for spatial representation can bring benefits throughout the decision-making exercise or planning process [32]. Dambruch et al. [15] noted that, for the purpose of the consultation, $3 \mathrm{D}$ models should appear as realistic as possible to be both understandable and convincing. On the other hand, Alatalo et al. and Semmo et al. argued that abstract representations provide better performance and can facilitate the recognition of information depending on the context [22,33]. Regarding 2D or $3 \mathrm{D}$ view, 3D has proven to be better in citizen participation by providing more realistic and natural details $[17,19]$. Although, Tory et al. argued that 2D and 3D are complementary and offer better problems resolution when combined [18].

\subsection{The Relevance of Time in Web-Mapping}

Time is considered as an important aspect of citizen participation as citizens want to follow the change evolution of their city and how their participation had an impact on it [2,6]. Marsouki et al. [21] noted the importance of spatiotemporal visualizations to enhance citizen participation in cities. However, with the emergence of $4 \mathrm{D}$ (3D spatial plus time) contents, there is a growing demand for $3 \mathrm{D} / 4 \mathrm{D}$ semiology and usability guidelines to help design $4 \mathrm{D}$ web-mapping in an efficient manner $[13,20]$. In this sense, Resch et al. $[13,20]$ studied 4D cartography in a user-centered context. Despite shortcomings such as distortions and occlusions, Resch et al. [20] argued that 3D cartographic representations are better than 2D representations for spatiotemporal phenomena.

\subsection{Time Representation}

In order to build a time-dynamic platform for citizen participation, two main components need to be considered: spatiotemporal analysis methods and time representation. Zheng et al. [34] gave an overview of spatiotemporal visual analytic methods in urban computing. One of the most common spatiotemporal analysis methods is data filtering [35]. Brovelli et al. [24] noted that data filtering can drastically maximize the performance and minimize the visual complexity by reducing the number of spatial layers shown simultaneously. Time itself is represented as a separate dimension through a timeline [36]. Animations are also used along with a timeline to help reveal hidden patterns in spatiotemporal phenomena [37]. Change in geospatial animations is manifested through a variation in graphical variables (e.g., color, texture, orientation, height, altitude) or by the appearance and disappearance of layers [24,38]. In this sense, Yin and Shiode [17] used multiple 3D city models where each model represents a time-step. They called for more works to study the correlation between the change in 3D city models and other variables such as population growth. Finally, Resch et al. [20] called for studies to assess the intuitiveness of $4 \mathrm{D}$ representations on the web so they can be improved.

\section{The Proposed Citizen Participation Platform}

\subsection{Design Framework}

\subsubsection{Citizen Participation}

A successful citizen participation platform must be intuitive, easy to manipulate, and respect usability criteria. Resch et al. [20] proposed a usability criteria list as a first iteration in the development of 3D/4D web maps. The platform interface is also based on the norm ISO9241-11 which provides a framework for understanding usability and provides definitions and applications [39]. Web-mapping interface designs can also be based on web-mapping tools commonly used by the public such as Google Maps and Earth, which are relatively well understood and simple in terms of usability.

The platform integrates a web questionnaire as its main participation tool. A questionnaire is relatively fast and easy to implement for cities and related institutions aiming to enhance their means to participate. Using a questionnaire enables statistical evaluation which can usually be done faster and easier than analyzing free-text feedback given in a chat room, forum or discussion board [15]. 
In our study, the questionnaire integrated multiple choice questions such as yes/no, choice of multiple answers, and free-text comments. We linked the questions in the questionnaire to multidimensional (2D, 3D, 4D) visualizations to show (1) the impacts of choices made during a consultation and (2) the evolution of urban planning projects. This will be further developed in the following sections.

\subsubsection{D/3D Representation}

Both 2D and 3D spatial representations were selected based on the information to be represented. In order to be more specific, we first determined if the information had a popular cartographic representation within current popular web-mapping tools, such as Google Maps. Otherwise, we used its natural representation in the real world. If the information to be represented did not have a natural representation in the real world (e.g., invisible phenomena) then we chose a $2 \mathrm{D}$ representation if the phenomenon was static and a 3D representation if the phenomenon was dynamic. This choice was made considering 3D is better to represent spatiotemporal phenomena [20]. All representations were designed according to norm ISO/TC-211 and OGC standards [40,41].

\subsubsection{Time Representation}

For simplicity purposes, space-time cube-based representations with time displayed on the $\mathrm{Z}$ axis were not considered in the proposed platform. Such visualizations can be complex to decode from a human perception standpoint [42]. Hence, we considered these methods not suitable for the public. Time was represented using a linear timeline, animations, charts, and data filtering.

Time is often represented by a linear timeline as it is less complex to manage and understand [36]. Animations are an efficient method to clearly communicate changes occurring in the space-time dimension [36]. However, animations reach their limits especially when long multivariate time series need to be visualized [37]. This problem worsens when multiple animations are used simultaneously. Therefore, one animation at a time is preferred. In such context, color was used to communicate the temporal order of a visualized phenomenon. Each time step of a phenomenon was represented by a color (e.g., blue) among a color scale (from white to blue). The environment encompassing the visualized phenomenon was coded in shades of gray for the color to reach its full potential in terms of perception [37]. Although the chart is a tool mainly used for visualization and statistical purposes, it can also be used for spatiotemporal analysis. The chart is undoubtedly the simplest time-related data visualization tool. The chart was used to explicitly establishes relationships between visualized two animations and provides the user with another perspective on these phenomena. Finally, data filtering was used to select only data to be viewed, for example by selecting a period. Data filtering was also used to reduce the number of elements shown and lower visual complexity and cognitive overload $[24,35]$.

\subsection{Architectural Components}

The software architecture of the designed web-mapping platform was based on a classic web system consisting of a server (back-end) and a client (front-end) (Figure 1). 


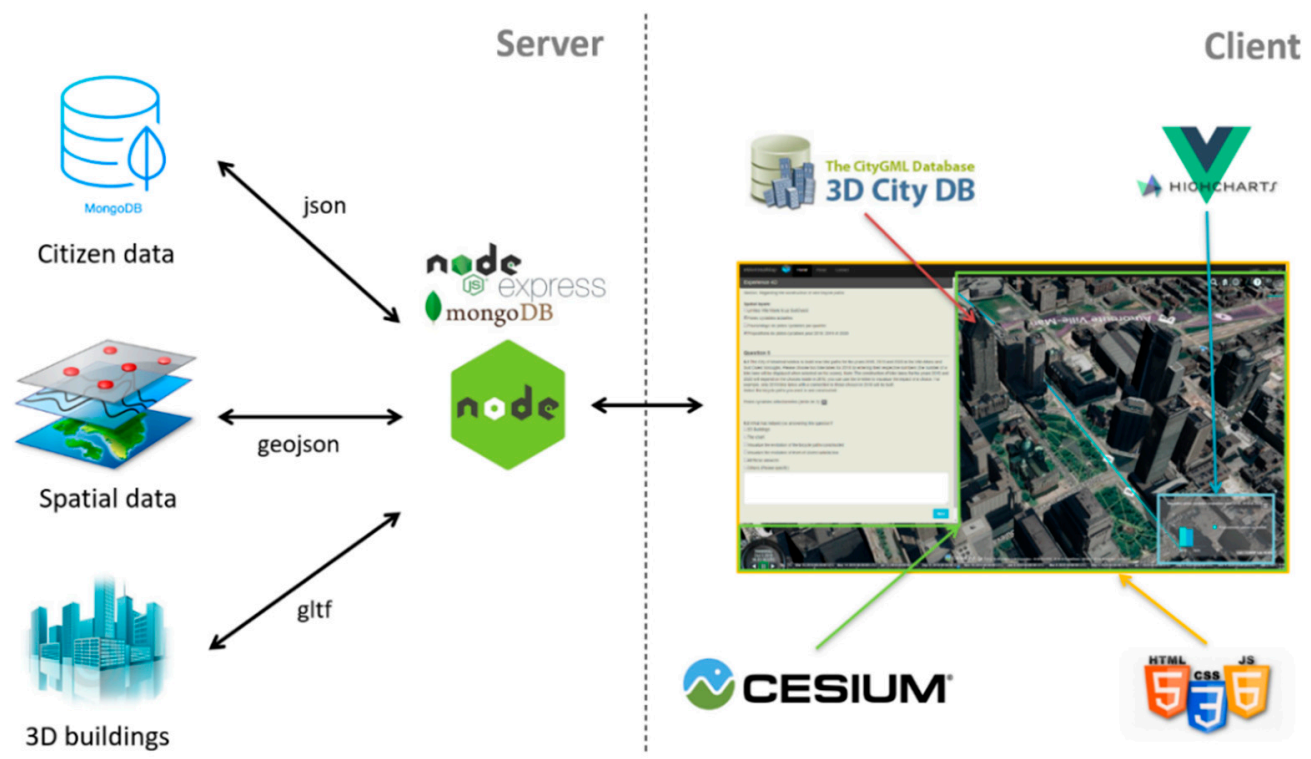

Figure 1. General software architecture.

\subsubsection{Server Side (Back-End)}

The server handles the requests coming from the platform. Normally, the requests are used to retrieve the information from the spatial data, 3D buildings and to store consultation information in the database. The server was developed in Node.js (v7.10.0) using the Express module (v4.4.4) and MongoDB (v3.4.9) as the database. The Express module is a minimal and flexible web application framework that provides a robust set of features for Web and mobile applications. Express is mainly used to render questionnaire forms, spatial layers, and contextual information from the database. Within the web server, spatial layers are stored in GeoJSON format (e.g., bike lanes, street constructions) and buildings in 3D JSON format called gITF. MongoDB was used with the Mongoose module (v4.12.2) for the database. MongoDB is a NoSQL database and document-oriented. MongoDB has been preferred to relational databases like PostGIS and NoSQL for primarily the easiness of altering and updating contents and for its good supports and documentation. These three technologies work well together as their common structure is the JavaScript Object Notation (JSON).

\subsubsection{Client Side (Front-End)}

Regarding the client side, Cesium.js, 3DCityDB, and Highcharts were used as main front-end technologies. Cesium.js (v1.39) is an open source virtual globe written in JavaScript to build time-dynamic 3D maps. 3DCityDB-Web-Map-Client (v1.4.0) was used to manage CityGML 3D building tiles within Cesium.js. More specifically, it handles the display of 3D buildings according to camera change (e.g., rotate, pan, zoom). The JavaScript Highcharts library was used to manage the charts (e.g., histogram, line plot, scatter plot) within the platform. The rest of the platform (e.g., interface) was developed using HTML5, JavaScript and CSS. Bootstrap (v3.3.7), and JQuery (v3.2.1) were also used in the development process.

\subsection{Key Components}

The proposed platform key architectural components concern two modules given the 4D capabilities targeted in this web-mapping platform: the 3D component and the spatiotemporal component. The next sections describe these two components in detail. 


\subsubsection{D Module}

The 3D component concerns the buildings integrated within the platform. Although Cesium.js's $3 \mathrm{D}$ tiles are now emerging as a powerful asset for rendering several buildings on a web application, at the time of this research investigation 3DCityDB-import-export was underlined as a useful tool to generate 2D tiles [31]. The 3DCityDB-importer-exporter process CityGML datasets, to generate gITF tiles ready to be rendered in Cesium.js. 3D buildings level-of-detail 2 (LoD2), with the texture of the city of Montreal in Canada were used in this process. The buildings were downloaded from the city of Montreal open data portal. Two models were processed, one without texture and one with texture.

Lovett et al. [30] noted that different stages of a planning process can benefit from various abstraction levels in visualizations to keep the participants' attention on relevant aspects. Hence, proposing multiple level-of-abstraction can facilitate the recognition of information depending on the context [33]. The authors also cite that using non-photorealistic rendering techniques can reduce visual complexity. Photo-realistic (with texture) provides more details and is often needed for better public acceptance [15]. Nevertheless, photo-realistic visualization offers less contrast since the colors can intermingle with the texture. We conducted benchmarking tests to discover the limit of buildings rendered for these two level-of-abstractions. The tests were conducted on a computer with the following characteristics: Intel Core i5-5200U CPU 2.20 GHz Dual-Core, 8.00 GB RAM, Intel HD Graphic 5500 GPU. The textured model was more demanding in machine resources, and we limited the number of visible buildings to 1000 for a viewpoint far away from the ground. For the non-textured model, the number of buildings shown simultaneously was set to 5000. The models with texture and without texture were used along with a Bing and Mapbox dark base map, respectively.

\subsubsection{Spatiotemporal Module}

This module refers to the spatiotemporal simulation mechanism designed for citizen participation. Based on the review conducted in this research, we selected three subcomponents for the mechanism: animations, timeline, and charts. The animations operate the change that occurred within the spatiotemporal layers. The charts display quantitative information related to the animations. Time management in Cesium involves a clock and a timeline. The clock manages everything related to the animation of the timeline: current time, backward or forward time, speed of animations, pause, play, or stop. The timeline is responsible for displaying the desired period with the start and end date. It also triggers events when the current time changes. Thus, given these features were already available in Cesium, they were used in the proposed platform. The remaining work consisted of linking animations and charts to these time-changing events.

\subsubsection{Geovisualization and Interaction Interface}

The geovisualization and interaction interface consist of five main parts: the questionnaire, the header, the toolbar, the scene, the clock and timeline (Figure 2). Several interface features were already integrated within the Cesium API. We developed dedicated functionalities, for example, to switch the level-of-abstraction from dark abstract buildings with Mapbox imagery to photo-realistic buildings with texture and Bing imagery, or to toggle 3D buildings or charts.

Several interactions and querying features were incorporated into the platform to allow the user to further explore the visualized data. If the view was enabled on the Cesium globe, the user can move around the scene with the usual navigation tools (i.e., pan, zoom, and rotate). The click, multiclick, and hover functions were programmed to interact with the spatial layers of the scene. The hover function highlighted entities when the mouse was overhead. The click function illuminated and displayed a window showing the attributes of the selected element. Finally, the multiclick function (ctrl + click) allowed the selection of several spatial entities in the scene. This functionality was useful to select choices during a real-time consultation scenario. 


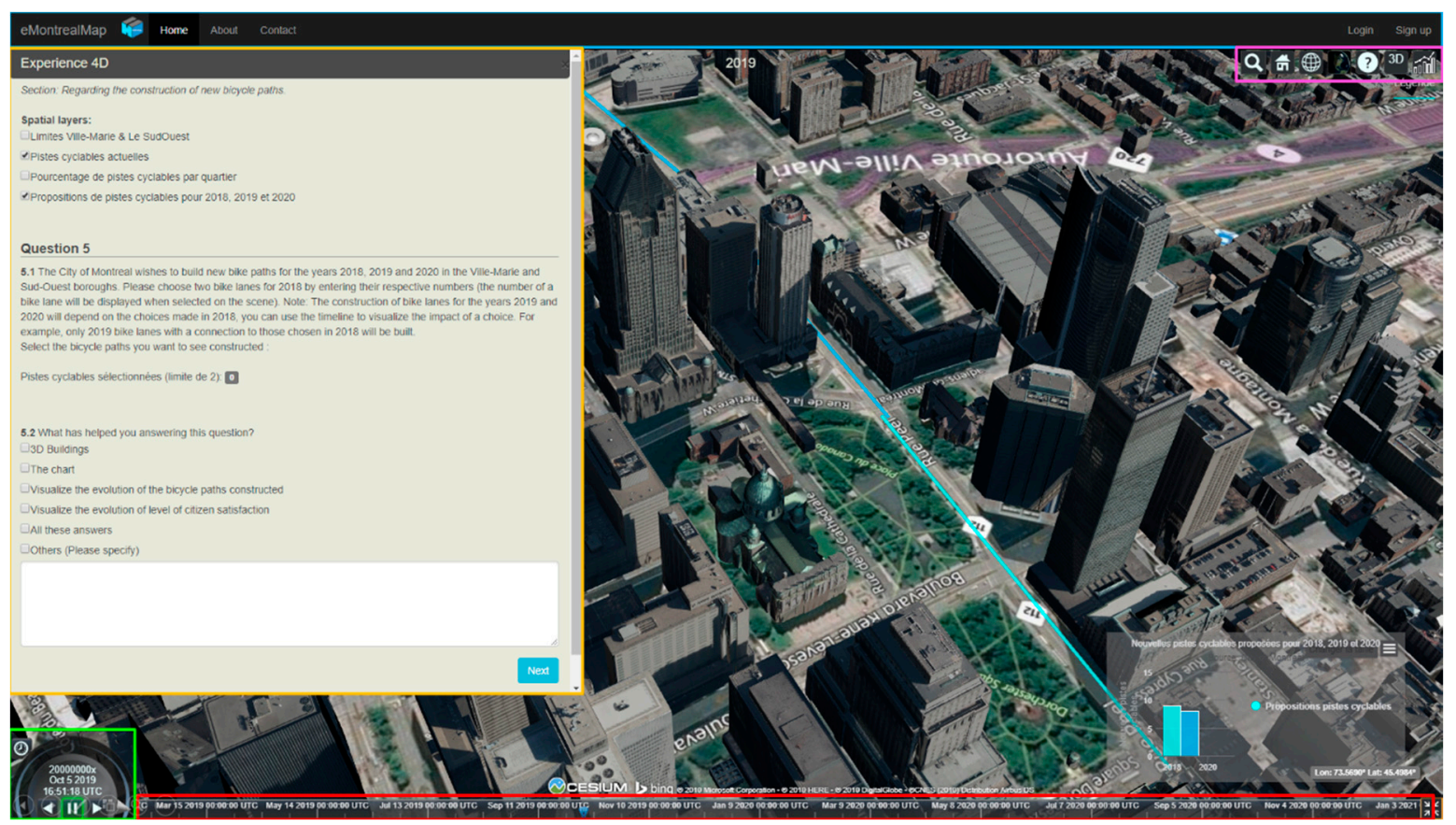

Figure 2. The questionnaire with the questions that users have to answer (here question \#5) is on the left (orange box); the header of the interface is at the top (blue box), the toolbar (pink box); the bottom left clock (green box) and the timeline (red box) at the bottom of the screen; the scene in the midst occupies the majority of the platform.

The user could also interact with the chart to further explore the illustrated data. The time period to visualize could be filtered, and the elements in the chart could be activated, or deactivated. The chart could also be resized and toggle on and off. These features provided the users with more flexibility and could reduce the amount of information displayed.

Within the questionnaire, users could toggle on and off spatial layers as they wished according to the current question. Spatial layers were chosen based on their relevance to the consultation topics. Users could interact with the spatial layers in the scene to learn more about the layer, and to approve or disapprove a project, for example.

Finally, guided tours were triggered at the beginning of a consultation scenario to show users the consultation context. To achieve that, the Cesium camera moved to show the area of interests in the consultation. During the tour, the timeline could be triggered automatically to show where the change occurred in the consultation.

\section{Deployment of the Proposed Platform}

Typically, cities are planning the next urban development phase for the forthcoming years at recurring periods (e.g., every five years). The plan comprises several priorities and development options. The development options are usually shown to the public during consultation meetings or by using traditional questionnaires. In such participation context, it is often difficult for the public to understand the impacts generated by a development choice. Visualization can be used to provide a common language for all the parties concerned (i.e., the citizens, stakeholders, and decision-makers) [4]. Hence, the deployment of the proposed platform used multidimensional visualizations and a web questionnaire to provide the public with a simple tool to assess the impacts of their choices during urban planning consultations.

In order to allow user testing of the platform, we designed five real case scenarios with the thematic of urban planning. The scenarios contained consultations questions where the users can use the multidimensional view to help them provide their answers. Scenarios one and two were used to 
introduce the platform features to the users so they can become familiar with them. This paper presents the scenarios four and five, which are the most relevant in terms of the results provided. For simplicity, we will refer to scenarios four and five as scenarios one and two for the rest of the paper. Scenario one concerns the implementation of new bicycle paths and the impact of choosing one bicycle path over the others. Scenario two concerns the construction of new high-rise buildings in four different neighborhoods and their impacts on urban density. This scenario was proposed by Yin and Shiode [17] to estimate the correlation between population change and urban development. Each scenario contained consultation questions and questions related to the design choices. The consultation questions served as a purpose for the users to participate and use the platform. The questions on the design choices evaluated the components of this platform. The whole platform setup and scenarios were tested with participants, and more details will be provided in the next section. In the current section, we will focus on describing the scenario in terms of design and features.

\subsection{Scenario One: The Construction of New Bicycle Paths in Downtown Montreal}

Within the platform, users had to choose the bicycle paths they wanted in the forthcoming years, namely from 2018 to 2020. Hence, they had to select, among several choices of bicycles paths, two paths they wished to see built in 2018. Once selected, a bicycle path appeared in pink and was added to the number of bicycle paths selected in the questionnaire (Figure 3). The selected bicycle paths in 2018 had an impact on those available in 2019 because of network connectivity. Therefore, users had to choose wisely the paths they wanted to include as part of the bicycle network. The spatiotemporal mechanism could be used to analyze the potential choices and foresee their impacts.

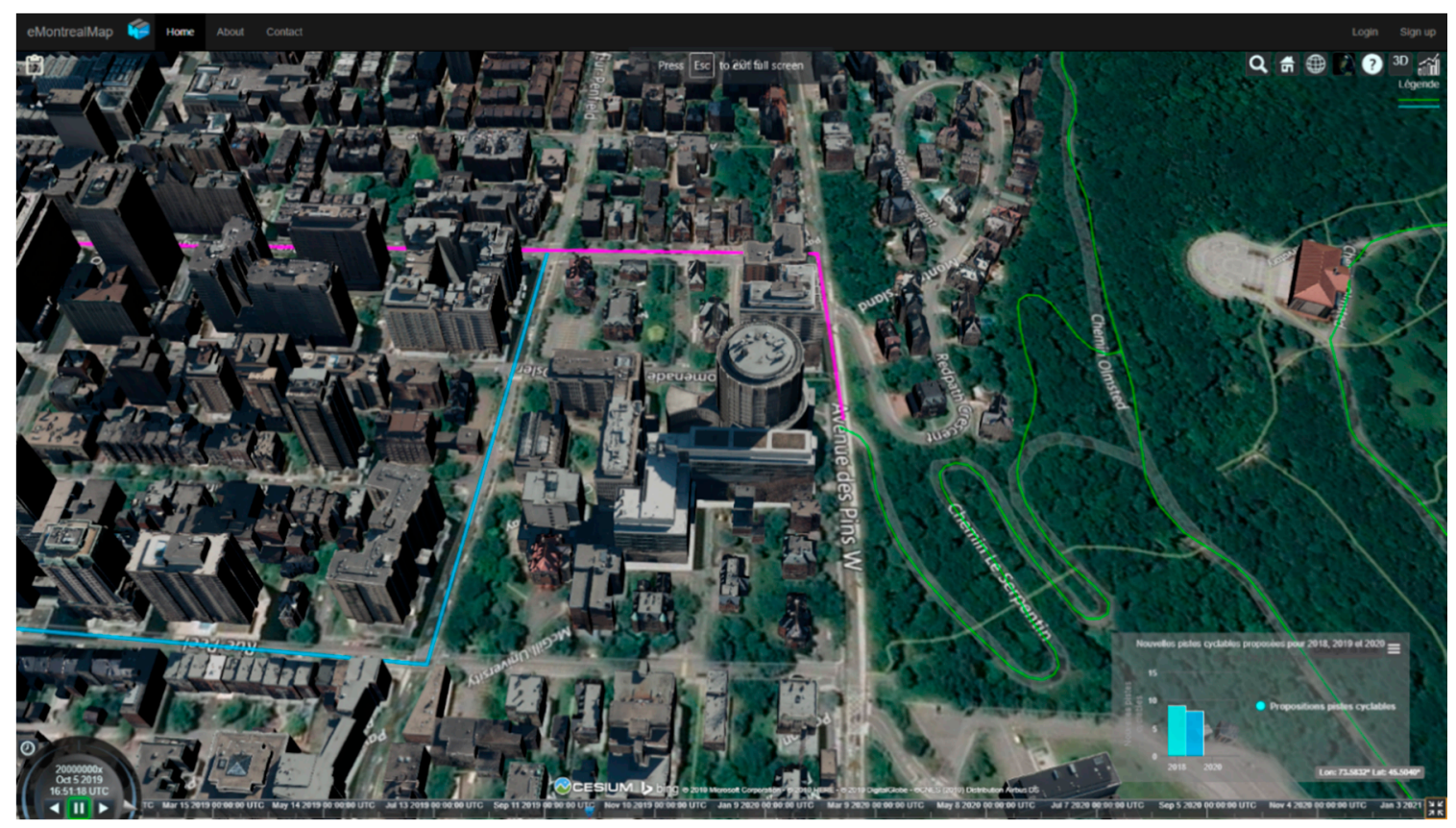

Figure 3. User case \#1 with selected bicycle paths in pink, future bicycle paths in blue, current bicycle paths in green, and realistic textured buildings with a Bing basemap imagery.

The spatial information displayed to assist this consultation were (1) future bicycle paths for 2018, 2019, and 2020 (2D + time animation); (2) buildings (3D); (3) current bicycle paths (2D); (4) administrative boundaries (2D). The timeline started in 2018 and ended in 2020, with an annual time step. The future cycle paths were linearly represented in 2D using a green color as the main graphical variable. A shade of blue was selected for each construction year (respectively dark blue for 2020, blue for 2019 and pale blue for 2018) (Figure 4). To simulate the bicycle path changes over time, the three components of the spatiotemporal mechanism were used. Thus, bicycle paths were animated according to the timeline 
change; they appeared only if their construction year was lower than the current year. With a bar chart, the number of bicycle paths proposed for each year was made explicit (Figure 4).

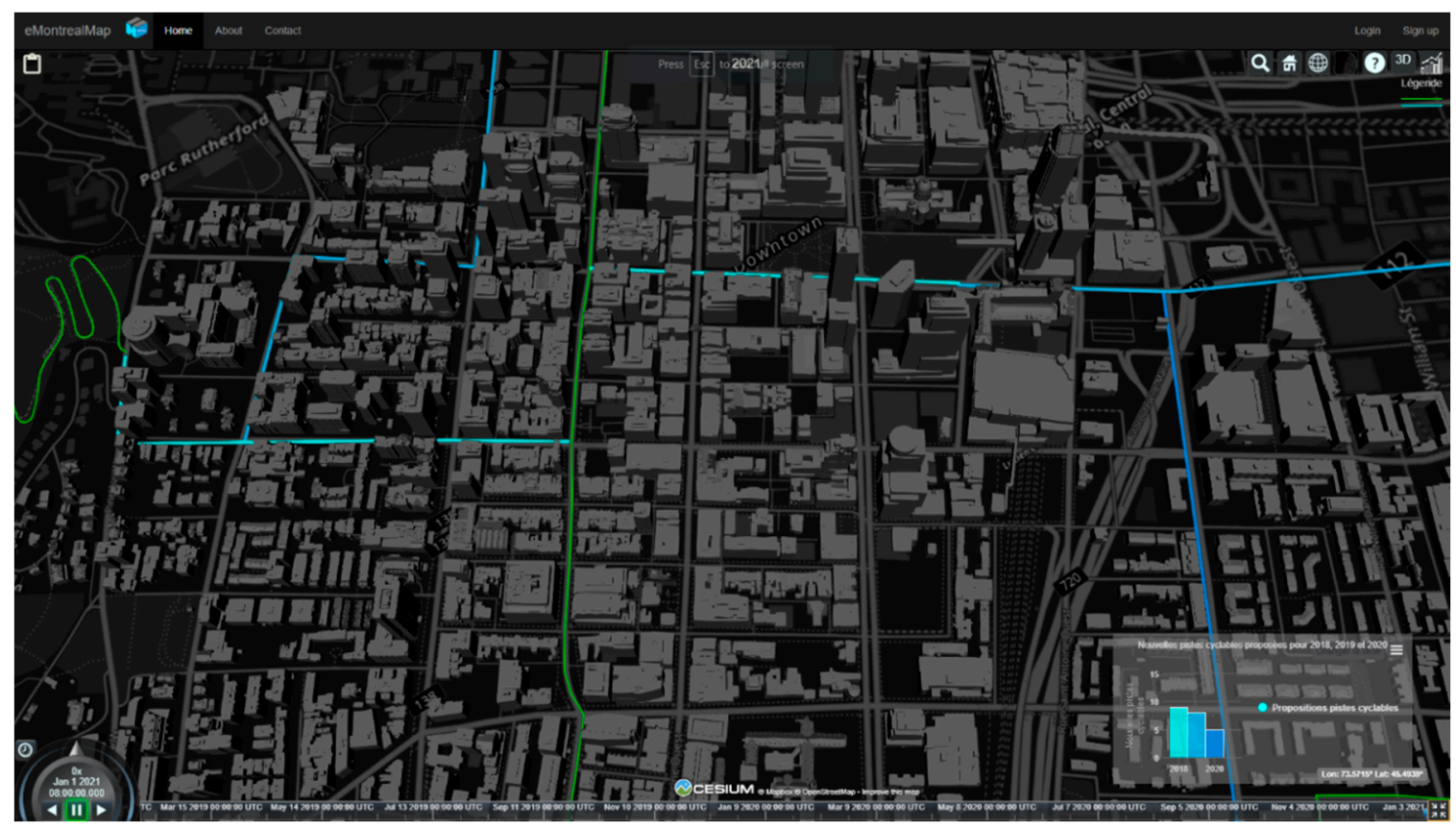

Figure 4. Scenario \#1 with future bicycle paths in shade of blue, current bicycle paths in green, and abstract non-textured buildings with a Mapbox dark basemap.

\subsection{Scenario Two: The Construction of New Buildings in Four Neighborhoods of Montreal}

This scenario concerned the construction of new buildings and their impacts on population density. In this context, four neighborhoods with different population density were selected since densification impact should be contextualized to the reality of the city neighborhoods. The first two neighborhoods were in downtown Montreal where there are high-rise and office buildings. The other neighborhoods were in residential areas where there are small houses. Similarly, as in the first scenario, users explored the impacts of their choices using the spatiotemporal mechanism. Within the proposed platform, users had to select and remove the buildings they did not wish to be built. Once selected, the building appeared in pink and the number of selected buildings was updated on the questionnaire. Population density was also updated, and the change was manifested through the animation and chart.

The spatial information displayed to assist this consultation user case were (1) future buildings for 2020, 2025, and 2030 (4D animation); (2) population density (4D animation); (3) the current buildings (3D representation); and (4) neighborhood boundaries (2D representation). The timeline started in 2020 and ended in 2030 and the time step was five years.

In order to simulate the changes due to the building construction, three components of the spatiotemporal mechanism were operated. The combined use of the animation and timeline triggered the display of the new buildings built in the city, respectively, 2020, 2025, and 2030. Transparency was applied to $4 \mathrm{D}$ animations to limit obstruction between buildings [42]. The temporal change was achieved via the disappearance and appearance of buildings and using color. The buildings encoded a blue gradient corresponding to its construction period (respectively, pale blue for 2020, turquoise for 2025, and blue for 2030) (Figure 5). The population density was represented by 3D regions corresponding to half-spheres. Each half-sphere encoded a color corresponding to a population density level (red for highly densified; orange for rather densified; yellow for medium density; pale green for little densified; and dark green for very little densification) (Figure 6). The volume and color of the half-spheres changed over time. An increase of the volume meant a spatial expansion of the neighborhood. A color change meant a change in population density manifested through the addition 
or removal of buildings. The color changed both in the scene and in the chart. In the chart, population density was represented by a column with one column per neighborhood.

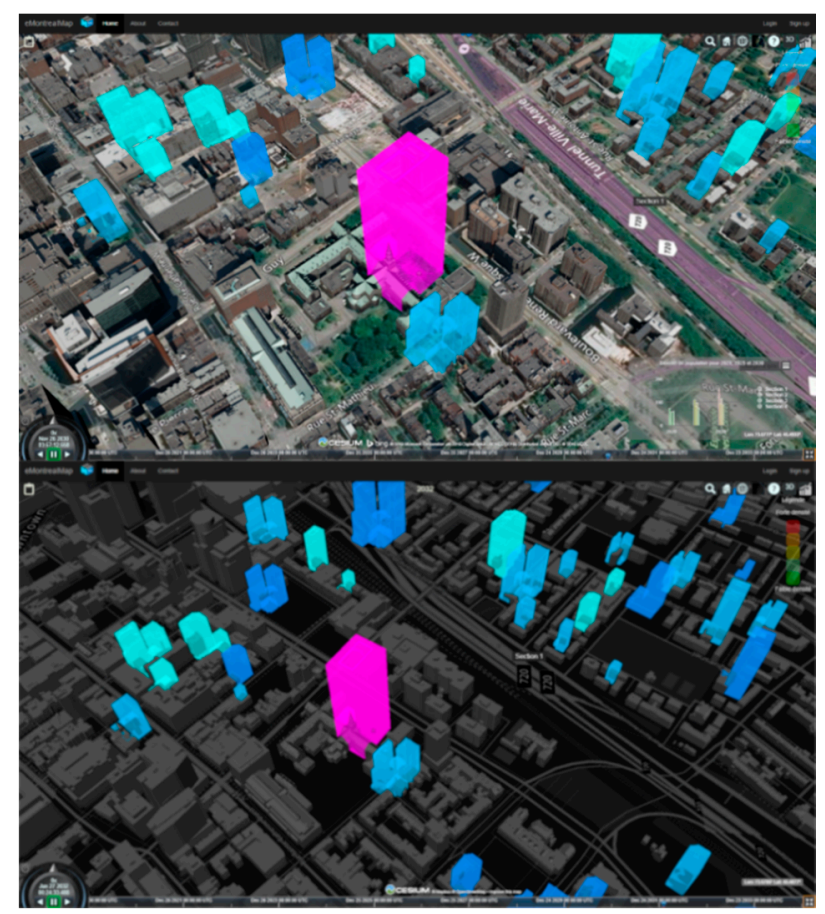

Figure 5. Scenario \#2 with future buildings proposed in different blue tone. The selected building is shown in pink and is planned to be built on a heritage site (i.e., church). Image also shows the realistic photo with texture.

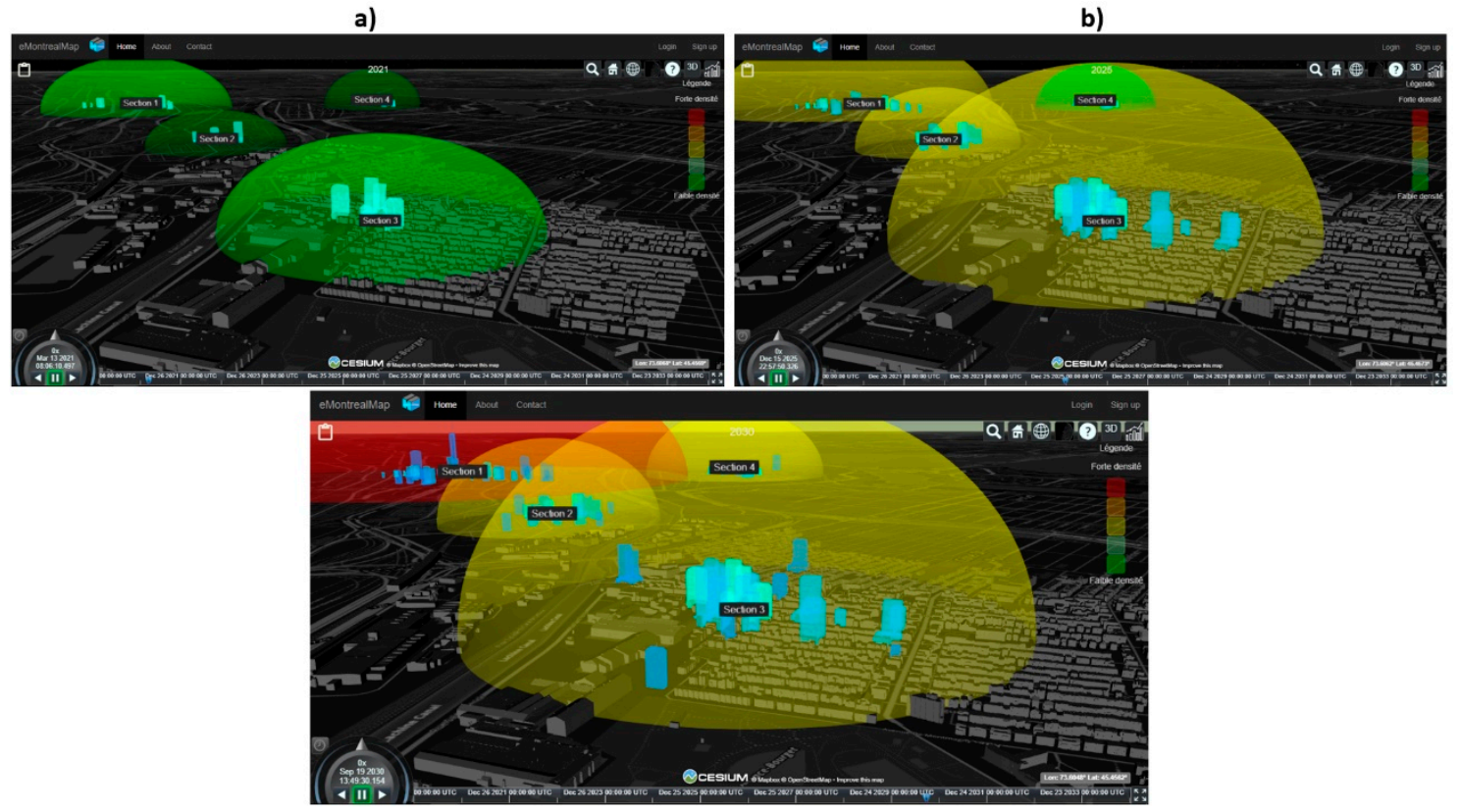

c)

Figure 6. All four neighborhoods with proposed high-rise buildings and projected population density at different periods: (a) 2020, (b) 2025, and (c) 2030.

\section{Evaluation of the Proposed Platform}

In order to assess the previous scenarios and the platform design choices, initial tests were conducted with 21 participants. The experiment was carried out at Laval University, Quebec, Canada 
in compliance with research ethics approval. The results are considered as preliminary since the participants were selected as a first iteration of software development. We did not evaluate the objectivity of the answers provided from the consultation questions. In fact, the results provided in this section aim at adapting the platform design choices in order to be further tested in a participation context with a more representative sample of participants.

During the experiment, each participant did the experiment alone. The first time a participant accesses the platform, a YouTube video of approximately 5 min was presented explaining how to use the platform. This also gave participants time to familiarize themselves with the platform features (e.g., timeline, changing level-of-abstraction). At any time, the participants could express their opinions on the platform and report any bugs or other technical or conceptual issues encountered. If they were stuck with a problem, they could ask the supervisor for help. Each time an intervention was made it was noted. The following questions were part of the platform questionnaire. Only the most relevant results are presented in this paper.

\subsection{User Study Questions}

Question 1 asked the participants to evaluate their level of experience regarding similar web-mapping tools and GIS. The participant indicated their experience using a single answer on a scale of 0 to 5 as follows: "No Experience" (5\%)_- "Some Experience" (9\%)—“Rather Experienced" (29\%)—“Experienced" (24\%)—“Expert" (33\%). We reassigned "No Experience"|"Some Experience" to "Inexperience" and "Rather Experienced"/"Experienced/"Expert" to "Rather Experienced". Thus, over $86 \%$ of the participants were considered as experienced. Participants were mostly students and researchers in the field of geomatics engineering, cognitive sciences, and information systems. The participants were selected consciously as a first iteration of a software development process to provide advanced feedback from a cartographic and user interaction viewpoint.

Question 2 asked how the participants subjectively perceived the 4D representation of buildings changes. This question was inspired by Resch et al. [13] and was asked in a hybrid form in five pre-defined categories ("Clarifying", "Stimulating Curiosity", "Confusing", "Fostering Process Understanding", "Other") plus the possibility for free-text comments. The participants could check only one category in their answer. Most persons found the animation fostered their understanding, clarifying and stimulating curiosity regarding the space-time development of buildings (Figure 7).

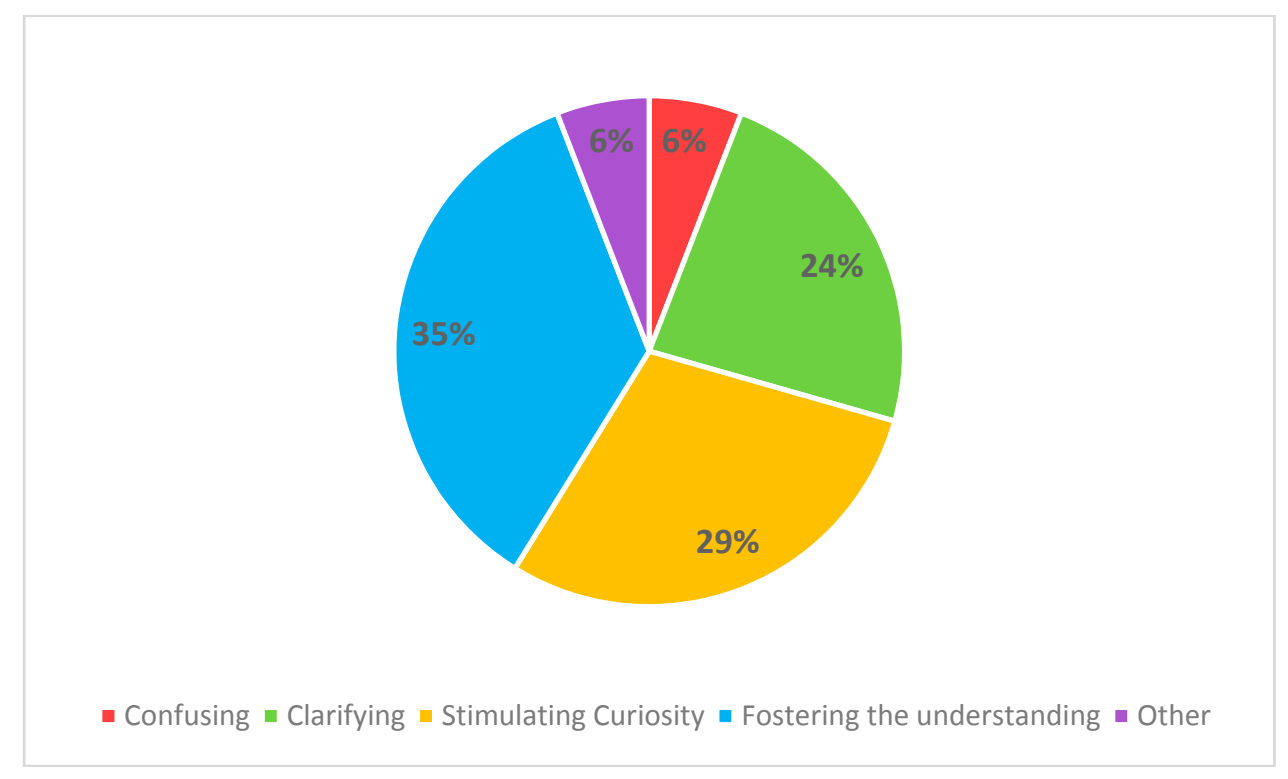

Figure 7. Assessment of the representation of 3D buildings using buildings with blue color scale appearing and disappearing through time. 
Not many free-text comments were provided to better understand the meaning of these results. However, one participant mentioned that "the animation is clarifying and increases the understanding with regard to the evolution of real estate development."

Question 3 asked how the participants subjectively perceived the 4 D representation of population density. The question operates the same way as for question 2. Most participants found that the animation fostered their understanding, clarifying and stimulating curiosity regarding the space-time development of population density (Figure 8). However, more confusion arose from the animation.

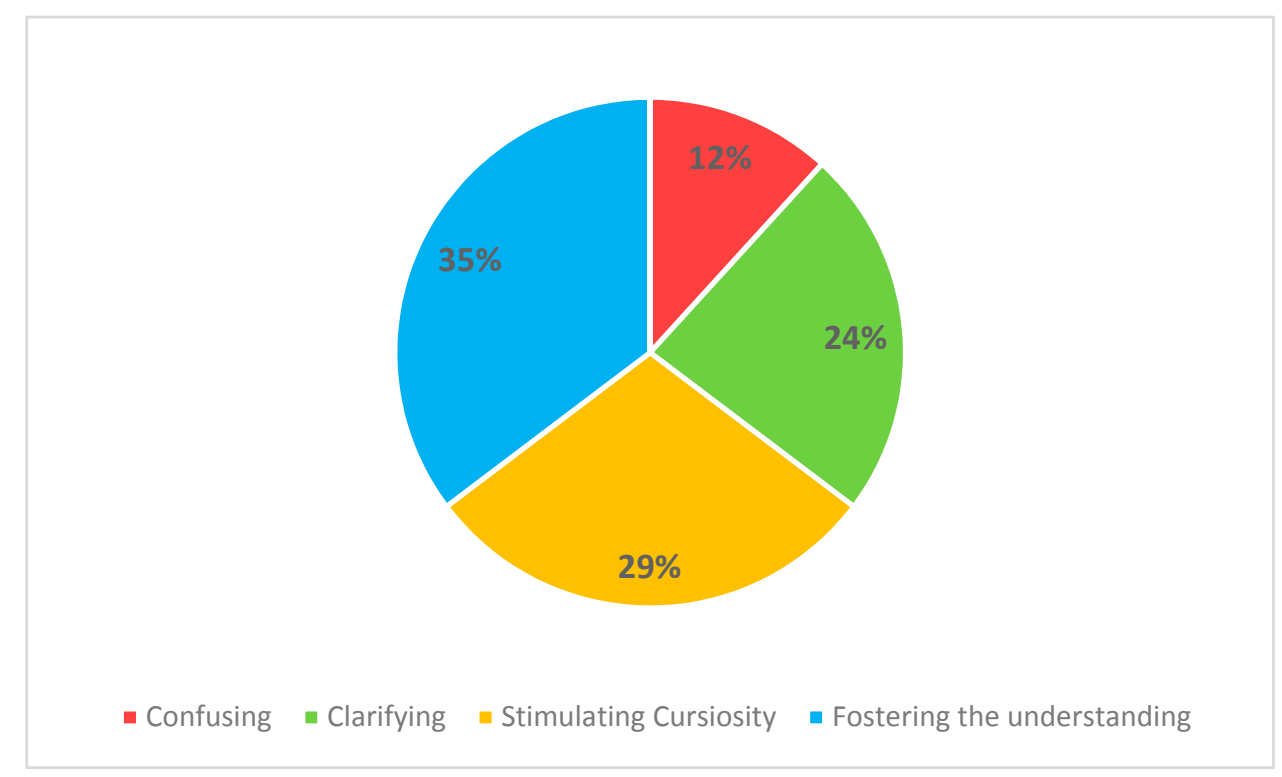

Figure 8. Assessment for the representation of population density using half-sphere, with color and size varying through time.

Analyzing free-text comments revealed that the confusion (to three participants) was caused by the change in both spatial and semantic for population density. One participant cited: "Representation by population density stimulates curiosity, but the perimeter increases with time, leaving me relatively confused." Another participant proposed to use a rectangle increasing in height instead of a half-sphere increasing in radius and color. What was interesting here was the two participants did not understand that indeed the area delineating new construction was expanding over time, hence the radius of the population density too. Nevertheless, a few participants, nine in total, verbally quoted they liked the representation. They clearly explained their enthusiasm mentioning twice that it was "nice-looking" and "interesting." Another participant even mentioned the use of population density helped to better guide his choices regarding the approval of certain buildings: "[...] the information on the density of the population guides me a little more in the realization of my choices."

The following questions were assessed in a hybrid form where users could rate on a scale of 0 to 10 (where 10 is totally agreed) plus the possibility for free-text comments. The questions, along with their scores and deviation, were synthetized (Table 1).

Question 4. The average score was 8.1/10 with a standard deviation of 1.6. This highlights that, for most participants, 3D was more effective than 2D in communicating spatial information. Nevertheless, the analysis of the comments revealed a divergence of opinions, as 13 out of 21 participants mentioned that 3D was not useful for visualizing 2D bicycle paths, whereas 3D proved to be relevant, even essential, for visualizing the construction of new buildings. A comment from a participant reads: "3D was useful for buildings, but not for bicycle paths." 
Table 1. Questions with associated mean $(\mu)$ and standard deviation $(\alpha)$ scores.

\begin{tabular}{|c|c|c|c|}
\hline$\#$ & Question & $\mu$ & $\alpha$ \\
\hline 4 & $\begin{array}{c}\text { In comparison with the 2D spatial dimension, did 3D spatial dimension allow you to better } \\
\text { understand the geographical context of the question, thus helping you to provide a more } \\
\text { informed answer? }\end{array}$ & 8.1 & 1.6 \\
\hline 5 & $\begin{array}{l}\text { Was the option of changing the style between "normal" and "dark" relevant to better understand } \\
\text { what was shown? For example, the "normal" style provided realistic details, while the "dark" } \\
\text { style provided emphasis on information of interest. }\end{array}$ & 7.6 & 2.5 \\
\hline 6 & $\begin{array}{l}\text { Were spatiotemporal simulations helpful to better understand the evolution of the information } \\
\text { concerned by the consultation (e.g., bicycle paths, buildings, population density)? }\end{array}$ & 8.4 & 1.6 \\
\hline 7 & $\begin{array}{l}\text { Were spatiotemporal simulations relevant to show future propositions and the impact of choices } \\
\text { made during a consultation process? }\end{array}$ & 9.1 & 1.3 \\
\hline 8 & $\begin{array}{l}\text { Was the chart useful to better understand the spatiotemporal evolution of information concerned } \\
\text { by the consultation (e.g., bicycle paths, population density)? }\end{array}$ & 7.9 & 1.4 \\
\hline 9 & Were the guided tours at the beginning of each consultation scenario relevant to put into context? & 6.6 & 3.0 \\
\hline
\end{tabular}

Question 5. The results obtained show an average score of 7.6/10 with a standard deviation of 2.5. In general, the participants agreed with the question, but there was some difference of opinion since the standard deviation was 2.5. We received positive feedback regarding the look of the abstract style. In this sense, some participants found the style "appealing" and "nice-looking". But some participants underlined that its main contribution was to provide more performance to the platform. These emphasize that the abstract style was not necessarily more useful for contrasting with other spatial information, but its usefulness came from its ability to be less demanding in terms of machine capacity. In this sense, two participants mentioned the utility of an abstract style to reduce machine capacity demands (e.g., CPUs, GPUs): "Under requests to the system, the abstract model appeared more useful than the realistic model."; "The abstract style has mainly been used to lighten the visualization of data". Although the abstract style offered better performance overall, it could also cause nuisance since more buildings were displayed simultaneously. This fact was mentioned by one participant: "There are too many buildings, and this considerably increases consumption of machine capabilities".

Question 6. The average for this question was 8.4/10 with a standard deviation of 1.6. This means that the participants generally recognized the importance of spatiotemporal simulations in a context where the spatial information concerned by the consultation has a temporal component. To this end, one participant mentioned that time was an important and relevant feature to better understand the phenomena involved. "Yes, the temporal component associated with space makes it possible to better understand the phenomenon under consultation. It was relevant to have it."

Question 7. The average score for this question was 9.1/10 with a standard deviation of 1.3. This shows that the spatiotemporal simulations offered the ability to visualize the impacts of the choices made during the consultation. The analysis of the comments made it possible to better understand the nature of this score. One participant mentioned that spatiotemporal simulations allowed citizens to better understand the plans offered by the city and its impacts. He also mentionned that this can go in favor of the city because a well-informed citizen can more easily accepts the decisions made by the city. Another participant mentioned: "Let us plan for the future to better understand planning and impacts. The message is better." Another participant mentioned: "The citizen least involved will want to see, understand, and especially give his opinion on the constructions in his sector. Not everyone understands the impact of decisions simply on paper reports, many are visual, and the application allows them to meet their needs."

Question 8. The average score for this question was 7.9/10 with a standard deviation of 1.4 . This showed that participants generally agreed with the relevance of the chart to support spatiotemporal simulations. One participant mentioned that the graph established quick links between the data in a simple way: "The graph allowed quick links between the different elements that were shown." Other participants quoted "The chart allows another visual aspect increasing comprehension!" "The chart is a good complement to the map, but it must remain as simple as possible." In addition, the graphic took up a lot of space in the screen according to one participant: "The graphic often took up a lot of screen 
space, especially with the open questionnaire." Nevertheless, the option to reduce its size or remove it was appreciated by three participants: "[...] I appreciated that we could reduce the size of the graph $[\ldots] . " ;$ "[...] it is interesting to have the possibility to display the graph or not". Another participant proposed to make its size adjustable to limit the occlusion of the scene "[...] Suggestion: The graph could be minimized".

Question 9. This question received an average score of 6.6/10 with a standard deviation of 3.0. In general, free-text comments analysis found that the guided tours were relevant. In this sense, one participant mentioned: "They allow us to put ourselves in context to help us understand what needs to be analyzed." Nevertheless, there should be more control over the guide tours. One participant mentioned: "Yes, they are relevant. However, the participant should have control over the guided tour. Otherwise, he does not know what is going on." By control, four participants mentioned offering the ability to advance or pass the guided tours, especially for experienced participants. Here are three of their quotes: "[...] an advanced user does not necessarily need guided tours to navigate. This can even affect its use."; "The guided tours are useful but it could be relevant to be able to pass them."; "Yes, but we should be able to pass the guided tours [...]". Other participants mentioned that they need to be improved at the design level to lighten the guidance and reduce the duration.

\subsection{Conclusion From User Study}

\subsubsection{Spatial Representations}

First, 3D in terms of representation and visualization can be more intuitive than 2D, especially regarding the construction of future buildings. According to some studies, the importance of a 3D representation can be justified when the information communicated has a natural 3D equivalent in the real world, because it corresponds to the mental model of the participant (e.g., building). Since buildings are naturally represented in 3D, it seems to be more appropriate to represent them as such.

An intuitive way of representing information is by having the exact representation stored within the mental model of a user. What is seen is what is known, as mentioned by Maceachren et al. [43], and the closer the representation is to the mental model of a user, the more intuitive will be the perception. Bicycle paths in cartography, for example, are often represented through a polyline encoding a color as graphical variable. Until we design a better way of representing bicycle path using 3D graphics, bicycle paths will be best represented in 2D. Therefore, we cannot conclude that $3 \mathrm{D}$ is always better than 2D in terms of intuitiveness. Because some spatial information, depending on the context, can be best represented in 2D and others in 3D. Finally, our results showed that a 3D environment with buildings was not useful when visualizing the evolution of 2D polylines representing bicycle paths. Our results also showed that when visualizing the evolution of 3D buildings, a 3D environment was better.

The participants could switch from one level-of-abstraction to another. The results showed that participants generally appreciated this feature. Although this feature is useful to provide more details and more focus on context, its main contribution is to be less demanding in terms of machine capabilities, thus improving the fluidity of the visualizations. Finally, this feature needs to be more prominently displayed, so participants know it exists. Additionally, it could be useful to parametrize this feature, so users could customize it as they want, as suggested by Semmo et al. [33]. Finally, developers must be careful when using this feature, as it may not be suitable for all consultation scenarios. An assessment of its benefit might be needed to prevent doubling the implementation effort associated with this feature.

Other limitations related to the representation and visualization of information concern the use of color as a main graphical variable and 3D. First, color has been widely used to encode information. However, it may be limiting for some people (e.g., colorblind) in a more participatory context. To this end, it would be necessary to offer the ability to switch from one graphical variable, such as color, to another, such as symbology. 3D can also be limited for people who do not see the perspective. 


\subsubsection{Performance}

Some negative feedback centered around the loading of buildings with 3DCityDB and Cesium.js. When viewing the animations, some buildings would still be changing, thus preventing the user from focusing on the context. To improve the building rendering performance, an option would be to display only what is needed. This could alleviate the visualization of the information shown. In addition, this could significantly reduce the number of asynchronous requests made and; therefore, increase the performance. Cesium 3D-tiles could also be used for better loading and rendering of buildings.

\subsubsection{Spatiotemporal Mechanism}

Regarding the spatiotemporal simulation mechanism and the monitoring of the impacts of the choices made during a consultation, the participants underlined its importance. The results also showed that spatiotemporal simulations help to better understand the impact of the choices made during a citizen consultation. Participants found the charts useful to quickly link the information displayed. The animations were generally well perceived, and the representation was valued by the participants. The results of this research also show that 3D animations are not necessarily always more intuitive than 2D animations, because it first depends on the spatial representation chosen for an information.

\subsubsection{Interface, Usability, and Experience}

Most of the participants liked the interface design as it prioritizes function over form. But there is still room for improvement. The guided tours at the beginning of each scenario to introduce the context was relevant, but they need to be improved. The first suggestion would be to improve the camera movements to better identify the spatial information involved in the consultation. The second improvement is to offer the ability to advance or pass the guided tours. The last improvement would be to block the user commands and add explanatory texts to better guide and understand the information that is shown through the tour.

The timeline was not user-friendly enough, and an average of three interventions per participant was noted. Interventions were mostly related to the use of the clock to control the animations and the use of the axis to forward or backward time. The timeline needs to be simplified, and a mix of tooltips and guided tours could be used to assist the user on its first visit.

Some participants struggled to interact with the globe, particularly with the half-sphere (i.e., population density) and the 3D buildings beneath it. The participants tried, unsuccessfully, to select the 3D buildings lying underneath the half-spheres. They had to zoom under the half-sphere to be able to query the building. This may be the sign that some of them lacked practice and experience with 3D maps and did not understand the hierarchical system of the layers. Yet, like 2D, the top layer must be disabled in order to pick up the layer lying underneath. This makes us question the usability of virtual globes in a participatory context, because if "experts" had difficulties in interacting with the globe, then there is a good chance that citizens will too.

The questionnaire associated with the multidimensional visualization was relevant, but the questions need to be simplified to maximize user experience and lower the chances of receiving a mistaken answer. Additionally, their answer might end up being out of scope and affect the results. In general, most participants found the experience too long (average length of $45 \mathrm{~min}$ ).

Overall, we received positive feedback from participants, and they agreed such a tool can increase citizen participation, and everyone was keen to participate if such a tool was made available by cities. However, the platform can be improved to be more useful to citizens.

\section{Discussion and Conclusions}

In this paper, we designed and developed a multidimensional web-mapping platform for citizen participation purposes, where users can better assess and understand the evolution of their cities 
through time. The proposed platform was built on top of the open virtual globe Cesium which relies on JavaScript and WebGL. Results have revealed that the spatiotemporal mechanism devised in this research, as well as its components (i.e., animations, charts, and timeline), are relevant to visualize and analyze the impacts of the choices made during a consultation. While $3 \mathrm{D}$ view is claimed to be better than 2D view in the literature, our results showed that a 3D environment with buildings was useful to visualize the evolution of 3D buildings, but not when visualizing the evolution of $2 \mathrm{D}$ polylines representing bicycle paths. Our findings suggest that both 2D and 3D spatial dimensions need to be included in a citizen participation platform, given that each of them may be useful or more intuitive depending on the information provided by different consultation scenarios. This aligns with and supports the same conclusions from Tory et al. [18]. Our study also showed participants appreciation in changing the level-of-abstraction from a photo-realistic style to a more abstract and darker style. This supports findings from Alatalo et al. and Lovett et al. [22,30], which claimed that multiple level-of-abstraction of the same information can help to better understand the consultation context. Finally, by using 4D representations and testing it with participants, our study answers Resch et al. called for the need for more assessment regarding $4 \mathrm{D}$ representations [20].

Although the approach needs to be tested with a representative sample of citizens, our results suggest that cities could benefit from using a similar approach to engage the citizens in decision-making, given that our approach seems to foster citizen participation in cities. Building on our results, citizen consultation related to road networks (e.g., bicycle paths, roads, public transport) could be assessed using a 2D polyline representation and environment only while buildings would benefit to be assessed through 3D representation and environment, as it has shown to be more intuitive for citizens. Finally, for abstract information such as population density, a 3D representation seems to be better for intuitively communicating spatiotemporal information to citizens.

This study has limitations. First, a 4 D representation was subjectively chosen for population density. This was done giving the scarcity of the literature regarding guidelines for $4 \mathrm{D}$ representations of abstract spatiotemporal phenomena. Another limit concerns the performance of the platform in the loading of buildings. Nowadays, end users require fast and fluid tools, and for this reason, we believe that poor building loading performance can affect user experience and have a negative effect on participation. Cesium 3D-tiles can be a potential solution to improve building performance.

Additional researches on 3D/4D semiology are needed to provide guidelines for designing spatiotemporal phenomena on the web, especially when such visualizations are presented to the public. Specifically, current 3D/4D representation approaches could be assessed using citizen participation indicators to know exactly when to use one approach for a scenario or situation. Given the current popularity of social networks where people meet and share contents, the platform could also benefit from being integrated into a social network to foster public participation. This could foster accessibility to GIS and the credibility of information shared through social networks. Artificial intelligence could also be used to analyze information shared through the network and provide useful indicators to decision-makers and citizens. Finally, additional tests will be done with a representative sample of citizens to improve the platform and highlight new research avenues.

Author Contributions: Conceptualization, Frederick Lafrance; Data curation, Frederick Lafrance; formal analysis, Frederick Lafrance; funding acquisition, Sylvie Daniel and Suzana Dragićević; investigation, Frederick Lafrance; Methodology, Frederick Lafrance; project administration, Sylvie Daniel and Suzana Dragićević; software, Frederick Lafrance; supervision, Sylvie Daniel and Suzana Dragićević; validation, Frederick Lafrance; Visualization, Frederick Lafrance; writing — original draft, Frederick Lafrance; writing_review and editing, Frederick Lafrance, Sylvie Daniel and Suzana Dragićević.

Funding: This research was funded by Mitacs Accelerate Canada, grants number IT06290 and IT09684. This research was also partially funded by NSERC Discovery Grant number RGPIN-2017-03939, which was attributed to the third author. The publication fees were funded by NSERC Discovery Grant number RGPIN-2018-04046, which was attributed to the second author.

Acknowledgments: We would like to thank the anonymous reviewers for their useful advice and feedback aiming at improving this paper. 
Conflicts of Interest: The authors declare no conflicts of interest.

\section{References}

1. Bryson, J.; Quick, K.S.; Slotterback, C.S.; Crosby, B.C. Designing Public Participation Process. Public Adm. Rev. 2012, 73, 23-34. [CrossRef]

2. Molinari, F. On Sustainable EParticipation. In Electronic Participation. ePart 2010. Lecture Notes in Computer Science; Springer: Berlin/Heidelberg, Germany, 2010; Volume 6229, pp. 126-139. [CrossRef]

3. Marzouki, A.; Lafrance, F.; Daniel, S.; Mellouli, S. The Relevance of Geovisualization in Citizen Participation Processes. In Proceedings of the 18th Annual International Conference on Digital Government Research-dg.o '17; ACM Press: New York, NY, USA, 2017; pp. 397-406. [CrossRef]

4. Al-Kodmany, K. Public Participation: Technology and Democracy. J. Archit. Educ. 2000, 53, 220-228. [CrossRef]

5. Salter, J.D.; Campbell, C.; Journeay, M.; Sheppard, S.R.J. The Digital Workshop: Exploring the Use of Interactive and Immersive Visualisation Tools in Participatory Planning. J. Environ. Manag. 2009, 90, 2090-2101. [CrossRef]

6. Nabatchi, T. Putting the "Public" Back in Public Values Research: Designing Participation to Identify and Respond to Values. Public Adm. Rev. 2012, 72, 699-708. [CrossRef]

7. Kingston, R. Public Participation in Local Policy Decision-Making: The Role of Web-Based Mapping. Cartogr. J. 2007, 44, 138-144. [CrossRef]

8. Smith, S.; Dalakiouridou, E. Contextualising Public (e)Participation in the Governance of the European Union. Eur. J. ePract. 2009, 7, 47-50.

9. Al-Kodmany, K. Visualization Tools and Methods for Participatory Planning and Design. J. Urban Technol. 2001, 8, 1-37. [CrossRef]

10. Sanford, C.; Rose, J. Characterizing EParticipation. Int. J. Inf. Manag. 2007, 27, 406-421. [CrossRef]

11. Daniel, S.; Doran, M.-A. GeoSmartCity: Geomatics Contribution to the Smart City. In Proceedings of the 14th Annual International Conference on Digital Government Research—dg.o '13; ACM Press: New York, NY, USA, 2013; p. 65. [CrossRef]

12. Hahmann, S.; Burghardt, D. How Much Information Is Geospatially Referenced? Networks and Cognition. Int. J. Geogr. Inf. Sci. 2013, 27, 1171-1189. [CrossRef]

13. Resch, B.; Hillen, F.; Reimer, A.; Spitzer, W. Towards 4D Cartography_Four-Dimensional Dynamic Maps for Understanding Spatio-Temporal Correlations in Lightning Events. Cartogr. J. 2013, 50, 266-275. [CrossRef]

14. Aigner, W.; Miksch, S.; Müller, W.; Schumann, H.; Tominski, C. Visualizing Time-Oriented Data-A Systematic View. Comput. Graph. 2007, 31, 401-409. [CrossRef]

15. Dambruch, J.; Krämer, M. Leveraging Public Participation in Urban Planning with 3D Web Technology. In Proceedings of the Nineteenth International ACM Conference on 3D Web Technologies-Web3D '14; ACM Press: New York, NY, USA, 2014; pp. 117-124. [CrossRef]

16. Yin, L. Integrating 3D Visualization and GIS in Planning Education. J. Geogr. High. Educ. 2010, 34, 419-438. [CrossRef]

17. Yin, L.; Shiode, N. 3D Spatial-Temporal GIS Modeling of Urban Environments to Support Design and Planning Processes. J. Urban. Int. Res. Placemak. Urban Sustain. 2014, 7, 152-169. [CrossRef]

18. Tory, M.; Kirkpatrick, A.E.; Atkins, M.S.; Moller, T. Visualization Task Performance with 2D, 3D, and Combination Displays. IEEE Trans. Vis. Comput. Graph. 2006, 12, 2-13. [CrossRef] [PubMed]

19. Hu, Y.; Lv, Z.; Wu, J.; Janowicz, K.; Zhao, X.; Yu, B. A Multi-Stage Collaborative 3D GIS to Support Public Participation. Int. J. Digit. Earth 2013, 8, 212-234. [CrossRef]

20. Resch, B.; Wohlfahrt, R.; Wosniok, C. Web-Based 4D Visualization of Marine Geo-Data Using WebGL. Cartogr. Geogr. Inf. Sci. 2014, 41, 235-247. [CrossRef]

21. Marzouki, A.; Mellouli, S.; Daniel, S. Towards a Context-Based Citizen Participation Approach. In Proceedings of the 10th International Conference on Theory and Practice of Electronic Governance-ICEGOV'17; ACM Press: New York, NY, USA, 2017; pp. 204-213. [CrossRef]

22. Alatalo, T.; Pouke, M.; Koskela, T.; Hurskainen, T.; Florea, C.; Ojala, T. Two Real-World Case Studies on 3D Web Applications for Participatory Urban Planning. In Proceedings of the 22nd International Conference on 3D Web Technology—Web3D '17; ACM Press: New York, NY, USA, 2017; pp. 1-9. [CrossRef] 
23. Brovelli, M.A.; Minghini, M.; Zamboni, G. Participatory gis: Experimentations for a 3d social virtual globe. Int. Arch. Photogramm. Remote Sens. Spat. Inf. Sci. 2013, 2, 13-18. [CrossRef]

24. Brovelli, M.A.; Hogan, P.; Prestifilippo, G.; Zamboni, G. Nasa WebWorldWind: Multidimensional Virtual Globe for Geo Big Data Visualization. Int. Arch. Photogramm. Remote Sens. Spat. Inf. Sci. 2016, 41, 563-566. [CrossRef]

25. Brovelli, M.A.; Minghini, M.; Zamboni, G. Public Participation in GIS via Mobile Applications. ISPRS J. Photogramm. Remote Sens. 2016, 114, 306-315. [CrossRef]

26. Brovelli, M.A.; Hogan, P.; Prestifilippo, G.; Zamboni, G. NASA World Wind: Virtual Globe for an Open Smart City. PeerJ. Prepr. 2016. [CrossRef]

27. Hu, Y.; Wu, J.; Lv, Z.; Zhong, H.; Yu, B. A Method for Representing Thematic Data in Three-Dimensional GIS. In 18th International Conference on Geoinformatics 2010; IEEE: Beijing, China, 2010; pp. 1-5. [CrossRef]

28. Murshed, S.; Al-Hyari, A.; Wendel, J.; Ansart, L. Design and Implementation of a 4D Web Application for Analytical Visualization of Smart City Applications. ISPRS Int. J. Geo-Inf. 2018, 7, 276. [CrossRef]

29. Wu, H.; He, Z.; Gong, J. A Virtual Globe-Based 3D Visualization and Interactive Framework for Public Participation in Urban Planning Processes. Comput. Environ. Urban Syst. 2010, 34, 291-298. [CrossRef]

30. Lovett, A.; Appleton, K.; Warren-Kretzschmar, B.; Von Haaren, C. Using 3D Visualization Methods in Landscape Planning: An Evaluation of Options and Practical Issues. Landsc. Urban Plan. 2015, 142, 85-94. [CrossRef]

31. Chaturvedi, K.; Yao, Z.; Kolbe, T.H. Web-Based Exploration of and Interaction with Large and Deeply Structured Semantic 3D City Models Using HTML5 and WebGL. In Bridging Scales-Skalenübergreifende Nah-und Fernerkundungsmethoden, 35; Wissenschaftlich-Technische Jahrestagung der DGPF; Deutsche Gesellschaft für Photogrammetrie, Fernerkundung und Geoinformation e.V.: Hamburg, Germany, 2015; pp. 296-306.

32. Hayek, U.W. Which Is the Appropriate 3D Visualization Type for Participatory Landscape Planning Workshops? A Portfolio of Their Effectiveness. Environ. Plan. B Plan. Des. 2011, 38, 921-939. [CrossRef]

33. Semmo, A.; Trapp, M.; Kyprianidis, J.E.; Döllner, J. Interactive Visualization of Generalized Virtual 3D City Models Using Level-of-Abstraction Transitions. Comput. Graph. Forum 2012, 31, 885-894. [CrossRef]

34. Zheng, Y.; Wu, W.; Chen, Y.; Qu, H.; Ni, L.M. Visual Analytics in Urban Computing: An Overview. IEEE Trans. Big Data 2016, 2, 276-296. [CrossRef]

35. Andrienko, N.; Andrienko, G.; Gatalsky, P. Exploratory Spatio-Temporal Visualization: An Analytical Review. J. Vis. Lang. Comput. 2003, 14, 503-541. [CrossRef]

36. Andrienko, G.; Andrienko, N.; Demsar, U.; Dransch, D.; Dykes, J.; Fabrikant, S.I.; Jern, M.; Kraak, M.; Schumann, H.; Tominski, C. Space, Time and Visual Analytics. Int. J. Geogr. Inf. Sci. 2010, 24, 1577-1600. [CrossRef]

37. Aigner, W.; Miksch, S.; Schumann, H.; Tominski, C. Visualization of Time-Oriented Data; Human-Computer Interaction Series; Springer London: London, UK, 2011. [CrossRef]

38. Nagarajan, M.; Gomadam, K.; Sheth, A.P.; Ranabahu, A.; Mutharaju, R.; Jadhav, A. Spatio-Temporal-Thematic Analysis of Citizen Sensor Data: Challenges and Experiences. In International Conference on Web Information Systems Engineering; Springer: Berlin/Heidelberg, Germany, 2009; pp. 539-553. [CrossRef]

39. International Organization for Standardization. ISO 9241-11:2018-Ergonomics of Human-System Interaction-Part 11: Usability: Definitions and Concepts. Available online: https:/www.iso.org/standard/ 63500.html (accessed on 19 January 2017).

40. International Organization for Standardization. ISO/TC 211-Geographic Information/Geomatics. Available online: https://www.iso.org/committee/54904.html (accessed on 19 January 2017).

41. Open Geospatial Consortium. OGC Standards | OGC. Available online: http://www.opengeospatial.org/ docs/is (accessed on 19 January 2017).

42. Dubel, S.; Rohlig, M.; Schumann, H.; Trapp, M. 2D and 3D Presentation of Spatial Data: A Systematic Review. In 2014 IEEE VIS International Workshop on 3DVis (3DVis); IEEE: Paris, France, 2014; pp. 11-18. [CrossRef]

43. Maceachren, A.M.; Wachowicz, M.; Edsall, R.; Haug, D.; Masters, R. Constructing Knowledge from Multivariate Spatiotemporal Data: Integrating Geographical Visualization with Knowledge Discovery in Database Methods. Int. J. Geogr. Inf. Sci. 1999, 13, 311-334. [CrossRef]

(C) 2019 by the authors. Licensee MDPI, Basel, Switzerland. This article is an open access article distributed under the terms and conditions of the Creative Commons Attribution (CC BY) license (http://creativecommons.org/licenses/by/4.0/). 